\title{
REFLETINDO SOBRE A AGÊNCIA DOCENTE ATRAVÉS DA OBSERVAÇÃO DE AULA ${ }^{1}$
}

Reflecting about teacher's agency by means of class observation

Janice Inês NODARI, UFPR ${ }^{2}$ Mariza Riva de ALMEIDA, UFPR $^{3}$

RESUMO:Este artigo se propõe a analisar o processo de observações de aulas como uma ferramenta pedagógica fundamental na formação inicial de profissionais da área de línguas estrangeiras na medida em que amplia possibilidades de percepção da agência docente. Para efetivar tal análise, cinco alunos de graduação do curso de Letras - Inglês da Universidade Federal do Paraná, em processo de formação inicial, atuaram como observadores de aulas no Centro de Línguas e Interculturalidade (Celin - UFPR) responderam um questionário em que refletiram sobre seus processos individuais. A partir das respostas dadas pelos participantes em relatórios crítico-reflexivos, associando subsídios teóricos relacionados ao papel da observação de aulas em BIAZI, GIMENEZ \& STUTZ (2011), sobre agência docente em LEFFA (2011) e ALMEIDA (2011), o estudo pretende aprofundar e desmistificar algumas visões associadas aos tópicos abordados.

PALAVRAS-CHAVE: Formação Inicial; Agência; Observação de Aulas.

ABSTRACT: This paper aims at analyzing the process of class observation as a fundamental pedagogical tool in the beginning of the teacher education process of professionals in the area of foreign languages, thus enlarging the perception of teacher's agency. In order to carry out such analysis, five undergraduate students taking "Letras" Languages - English at the Federal University of Paraná, acted as class observers at Celin - Center of Languages and Interculturality. The five students were all in the initial phase of their teacher education programme, observed classes and answered a questionnaire in which they reflected about their individual processes. From the answers provided by the participants in critical-reflexive reports, along with theoretical subsidies related to the role of class observation provided mainly by BIAZI, GIMENEZ \& STUTZ (2011), and to teacher's agency in LEFFA (2011) and ALMEIDA (2011), the study hopes to broaden and demystify some of the views related to the topics dealt with.

KEY WORDS: Teacher Education Proces; Agency; Class Observation.

\footnotetext{
${ }^{1}$ Gostaríamos de agradecer à professora Jeniffer Albuquerque por ter lido uma das primeiras versões deste texto e por ter feito contribuições valiosas para a redação do artigo.

2 Professora de Língua Inglesa do DELEM-UFPR. Mestre em Letras-Inglês pela UFSC.

${ }^{3}$ Professora de Língua Inglesa do DELEM-UFPR. Doutora em Letras pela UFPr.
} 


\section{INTRODUÇÃO}

Nosso campo de atuação diz respeito aos alunos de Letras - Inglês da UFPR Universidade Federal do Paraná - que podem, ao longo de seu curso, participar de programas de estágio desenvolvidos no Celin - Centro de Línguas e Interculturalidade. O Celin configura-se em esfera significativa para o desenvolvimento de práticas de aprendizado de línguas estrangeiras e tem se destacado como espaço de integração dos alunos de Letras da UFPR à prática docente por meio de oportunidades de estágio extracurricular, incentivo à pesquisa e produção científica. É oportuno ressaltar que nossa área de atuação se aplica a línguas estrangeiras de forma geral, preservadas as especificidades de cada língua. Isto posto, por força de nossa atuação como formadoras de professores de Língua Inglesa, os participantes deste estudo são todos advindos do curso de Letras - Inglês da referida universidade.

Neste campo de atuação, mas não se restringindo apenas a ele, entendemos o processo de observação de aulas como uma ferramenta pedagógica fundamental na formação inicial de profissionais da área de línguas estrangeiras na medida em que amplia possibilidades de percepção da agência docente. Mas o que se entende por agência docente e como se dá a relação entre o professor regente e o estagiário observador?

Para a pesquisadora Mariza Almeida (2011), na conceituação do termo agência, é preciso não perder de vista

os diferentes papéis a serem desempenhados por cada indivíduo envolvido no processo de formação, em face de diferentes situações enfrentadas ao longo deste processo. Trata-se de um processo de construção contínua de identidades, que se constituem na interação com outros sujeitos em diferentes situações, não sendo fixas, já que cada contexto poderá determinar o uso de uma - ou mais identidade(s) do sujeito (ALMEIDA, 2011, p. 66).

É, portanto, pela observação de aulas e de diferentes aspectos de ensino e aprendizagem que ocorre a interação entre professor e estagiário, já que este entra em contato com o universo de papéis distintos desempenhados pelo professor, e, na sua relação com a sala de aula, com os alunos e com o professor agente, passa a dividir ideias e 
tem oportunidade de propor questionamentos, dúvidas e sugestões. Portanto, o estagiário ${ }^{4}$ passa a ter um papel ativo desempenhando também diferentes agências nas situações com que se depara.

Por ser vista como ferramenta de prática pedagógica, é possível associar às observações de aula inúmeras vantagens, dentre elas o fato de que os professores regentes e os professores em potencial, os estagiários, se beneficiam uns das experiências dos outros. Além disso, as observações podem criar uma espécie de sistema de suporte na medida em que ao abranger o todo, tanto aspectos positivos quanto negativos da sala de aula poderão ser vivenciados. Não se pode perder de vista o fato de que há uma tendência a se concentrar a atenção mais em pontos negativos do que positivos quando se está observando e não conduzindo uma aula. Daí a importância de uma visão holística que englobe não só momentos de instabilidade ou problemas, mas sim todo o processo com seus pontos mais ou menos marcantes. Esta visão holística engloba uma

relação de interdependência entre prática e teoria, uma relação entre homem e mundo, a "práxis" freiriana. Uma relação dialética sempre difícil que inclui contradições e conflitos constantes entre ambas, que servem de ponto de partida para a busca de novos caminhos, gerando transformações nos contextos em que vivemos, ou seja, no mundo em que somos, estamos e agimos e em nós mesmos. Nas palavras de Freire (1983, p. 40), "[...] a práxis, [...], é ação e reflexão dos homens sobre o mundo para transformá-lo". Portanto, é através da prática, aliada à teoria, que agimos sobre o mundo para transformá-lo. Este processo é especialmente evidente na área das Ciências Humanas, que trabalha num espaço de conhecimento em que o elemento humano é fundamental nos estudos desenvolvidos (ALMEIDA, 2011, p. 73).

Cumpre ressaltar ainda que a observação de aulas viabiliza o desenvolvimento didático-pedagógico e o amadurecimento do pensamento crítico-reflexivo. Estes aspectos são necessários ao exercício da profissão de professor de línguas e à manutenção de uma postura continuamente questionadora e transformadora, como já apontado pela pesquisadora Maximina Freire ao se referir ao estágio como componente curricular (2011). No caso dos observadores do Celin, a prática realizada referia-se à observação de aulas em momento anterior ao estágio, e este não era o estágio obrigatório.

\footnotetext{
${ }^{4}$ Para fins de simplificação, toda vez que fizermos referência aos termos "estagiário" ou "observadores" estaremos nos referindo aos alunos de graduação que observaram aulas no Celin e que são os sujeitos dessa pesquisa.
} 
Para que as observações tenham o efeito esperado, um planejamento prévio é essencial. Os envolvidos - professores a serem observados, estagiários observadores, alunos das turmas a serem observadas e supervisores - precisam estar cientes de que o processo irá ocorrer, e a logística do mesmo deve ser estabelecida a priori. Assim, datas, conteúdos a serem trabalhados, quem observa quem, como será feita a observação, troca de informações entre observador e observado são alguns dos aspectos que não podem ser negligenciados sob pena de comprometer os resultados esperados.

Discussões incluindo os observadores e os observados com o formador de professores podem ajudar na criação de uma identidade de grupo bem como fornecer as ferramentas para uma tomada de decisões mais embasada em termos teóricos a partir das leituras e discussões feitas. No caso específico desse estudo, as discussões se concentraram na definição do que seriam observações de aula, e em possíveis formatos de relatórios para registro das observações feitas (anexo 2). Também foram discutidas as diferentes etapas de uma aula, as formas de trabalho e eventuais habilidades trabalhadas - leitura, escrita, compreensão e produção oral, pensamento crítico e domínio de ferramentas tecnológicas, e a inter-relação entre elas, considerando uma visão de trabalho não compartimentalizada, mas sim de junção de multi-letramentos.

Todo esse processo de discussão, estudos, escolhas e trabalho com visões e experiências de mundo diferenciadas - e muitas vezes conflitantes - entre os participantes, foi proveitoso, e os embates, vistos sob uma perspectiva positiva de crescimento e redimensionamento constante de posições, foram incentivados. Como defendido por Almeida (2011),

se vivemos em comunidade e acreditamos que cada ser humano é único, não há como nem porque suprimir a existência de conflitos entre as pessoas, já que diferentes interpretações e ideias estarão sempre em jogo em situações de interação e é graças aos pontos de atrito, fricção e conflito que se produzem novos sentidos.

Há uma tendência a se encarar conflito e embate como carregados de significação negativa. Vejo, entretanto, na construção de sentidos destes conceitos, a possibilidade de se enxergar o conflito como algo positivo, já que se trata de uma possibilidade de aprendizado para todo ser humano: aprendizado em termos de estratégias de ação e diferenças individuais quando nos defrontamos com situações conflituosas; aprendizado no reconhecimento de nossas limitações e na necessidade de posicionamentos; aprendizado no desenvolvimento de uma capacidade argumentativa e uma visão de mundo aberta para confrontações com diferentes visões de mundo (ALMEIDA, 2011, p. 30). 
Maximina Freire (2011) chama atenção para a presença de tensões também entre as teorias discutidas já ao longo do curso de licenciatura e a prática vivenciada em aulas observadas e aponta que, no período do estágio,

[o] descompasso entre o prescrever/realizar e o dizer/fazer, nesses dois contextos, pode ser tão impactante que, por vezes, desestabiliza as concepções e representações dos futuros professores e abala - temporária ou definitivamente

- a escolha profissional e a decisão de investir em uma carreira docente (2011, p. 266, grifo no original).

Tais observações apontam para a importância do estágio na formação inicial do professor. O que pretendemos é mostrar que o período de observações de aula, incluído no estágio, é fator decisivo na formação do profissional da área de línguas estrangeiras. Importante ressaltar que, para nós, a observação de aulas deve ser uma constante na carreira de todo professor.

Encontramos embasamento no trabalho de Terezinha Biazi, Telma Gimenez \& Lídia Stutz (2011), para a construção de significados a respeito do papel da observação de aulas na formação inicial do profissional de Letras. Enfatizamos, porém, que o processo aqui analisado não é parte integrante do estágio curricular obrigatório e que, portanto, atendia a outras demandas que não àquelas propostas e que regem o estágio em licenciaturas, muito embora haja no momento um estudo para que o estágio realizado no Celin se configure em uma das possibilidades de estágio obrigatório dos formandos de Letras da UFPR.

\section{METODOLOGIA APLICADA}

Compartilhando a visão de Jack Richards \& Charles Lockhart (1996), para este trabalho, a observação de aulas é entendida como uma forma de coletar informações sobre ensino, muito mais do que uma forma de avaliar o ensino. Além disso, Thomas Farrell (2005) defende que a observação de aulas serve de exemplo de prática reflexiva, pois faz com que o futuro professor pondere sobre o que viu em sala, pense em por que isto aconteceu e considere outras possibilidades de atuação para o professor. Justamente porque muitos professores relacionam a observação de aula a um instrumento de avaliação, há certa relutância tanto em fazer observações quanto em ser observado. 
Na perspectiva da observação de aula como uma experiência positiva é que propusemos, enquanto supervisoras do trabalho a ser desenvolvido, que os cinco participantes, ao observarem as aulas pré-acordadas no grupo, se limitassem a tomar notas dos procedimentos das aulas, da postura do professor e dos alunos.

Apesar de entendermos e postularmos que as observações podem e devem propor formas de participação diferenciadas por parte dos observadores, nesse caso específico, foi acordado que os observadores não tomariam parte ativa em qualquer momento da aula, concentrando-se na observação per se, numa atitude, tanto quanto possível, de não interferência.

\subsection{Caracterização dos sujeitos envolvidos}

Os envolvidos nessa pesquisa foram em número de 15, entre estagiários observadores e professores observados, além da coordenação pedagógica da área de língua inglesa e da assessoria pedagógica, ambas envolvidas na formação de professores de línguas estrangeiras, neste caso específico da língua inglesa.

Sendo esta pesquisa de cunho qualitativo, e dado o escopo que a mesma assumiu em função de trabalhar com grupos diferenciados, optamos por relatar a análise das respostas fornecidas em questionário aplicado apenas aos estagiários observadores, mesmo de posse das respostas fornecidas em outro questionário pelos professores observados. A escolha pelas pesquisas de cunho qualitativo se justifica, de acordo com Almeida (2011, p. 88), pois estas "via de regra, ampliam significativamente o escopo de atuação tanto do pesquisador quanto dos sujeitos das pesquisas".

Ainda Antonio Chizzotti (2006, p. 28) nos diz que

a pesquisa qualitativa recobre, hoje, um campo transdisciplinar, envolvendo as ciências humanas e sociais, assumindo tradições ou multiparadigmas de análise, derivadas do positivismo, da fenomenologia, da hermenêutica, do marxismo, da teoria crítica e do construtivismo, e adotando multimétodos de investigação para um estudo de um fenômeno local em que ocorre, e, enfim, procurando tanto encontrar o sentido desse fenômeno quanto interpretar os significados que as pessoas dão a eles (apud ALMEIDA, 2011, p. 88). 
É importante esclarecer que as ferramentas metodológicas usadas nas pesquisas educacionais são usualmente determinadas pela visão de mundo dos pesquisadores. Com base nessa compreensão, pesquisadores com uma visão realista-objetivista de mundo tendem a utilizar pesquisas quantitativas em seus trabalhos, enquanto que os que possuem uma visão idealista-subjetivista de mundo tendem a utilizar pesquisas qualitativas, que levam em consideração as interpretações dos pesquisadores (SANTOS FILHO, 1997, apud ALMEIDA, 2011, p. 88-89). Por nos enquadrarmos no segundo grupo, optamos pelo uso da análise qualitativa, e consideramos que o processo educacional deve ser analisado e repensado constantemente.

\subsubsection{O grupo de observadores}

Os observadores participantes desse estudo foram em número de 08, mas apenas 05 destes responderam ao questionário que propusemos. Assim, na perspectiva da análise qualitativa que leva em consideração o envolvimento dos participantes e seu real interesse pelo estudo, demonstrado por suas respostas às demandas solicitadas, passamos a considerar os participantes como os sujeitos da pesquisa.

Os 05 participantes tinham entre 20 e 24 anos, sendo 04 mulheres e 01 homem, e, como já colocado anteriormente, eram estudantes de graduação em Letras - Inglês, Licenciatura ou Bacharelado. Destes, dois não apresentavam experiência alguma como professores, e três apresentavam experiência variando de poucas semanas a 03 anos no ensino de língua inglesa. Interessante apontar que apesar de o estágio no Celin focalizar prioritariamente alunos de licenciatura, ponderamos que o interesse demonstrado por alunos de bacharelado poderia significar um interesse pelo ensino e talvez uma opção pouco informada quando da escolha pelo bacharelado. Resolvemos, assim, acolhê-los para que pudessem conhecer esta possibilidade para sua formação profissional.

\subsubsection{Proposta para coleta de informações}

Os estagiários observadores tiveram a oportunidade de participar de dois momentos de observações de aulas. Num primeiro momento, os estagiários observadores receberam nomes e horários de aulas dos professores que concordaram em ter suas aulas observadas. Os observadores tiveram então a oportunidade de acompanhar algumas aulas 
destes professores, em níveis e turmas variadas, de forma esparsa. Além disso, em função do tamanho das salas de aula e das turmas observadas (média de 15 alunos em sala por turma), optou-se por ter apenas um estagiário observando cada aula, com algumas exceções em função da disponibilidade de horário deles.

Em um segundo momento, os estagiários observaram aulas de determinado nível (sendo este o nível que, dependendo de seu envolvimento, poderiam vir a assumir como professores estagiários no semestre seguinte), durante um período de aproximadamente 04 semanas, com aulas de segunda a quinta-feira. Este segundo momento, porém, será analisado em outro artigo dado o grande escopo de dados coletados.

Ao optar pelo estudo do primeiro momento em que a observação de aulas se deu de forma esparsa, sem seguir uma sequência, sabíamos que a coleta de subsídios seria limitada, no entanto, não menos importante.

Não fossem a limitação de espaço e a disponibilidade dos observadores, analisar simultaneamente os dois momentos observando o cruzamento de informações levantadas de uma mesma aula, segundo diferentes pontos de vista, certamente forneceria insumos relevantes sobre estilos de ensino e aprendizagem, e mesmo perspectivas diferentes sobre a condução das atividades, ou técnicas de correção, para citar alguns exemplos. De qualquer forma, os dados coletados pelos participantes se constituiram em rico material de pesquisa sobre a sala de aula de língua inglesa para as discussões de grupo estabelecidas e poderão ser usados em novos estudos.

Feita a opção pelo primeiro momento, alguns resultados foram logo percebidos. $\mathrm{O}$ ensino e aprendizado de língua inglesa, sem mencionar o retorno imediato para os professores observados na forma de relatórios por escrito de suas aulas e para os estagiários que observaram aulas em um ambiente em que não se encontravam como alunos, foi extremamente relevante.

Além disso, entendemos que as observações no Celin ocorreram em um ambiente privilegiado, já que distinto do comumentemente encontrado, quando as observações de aula são solicitadas no período anterior ao estágio supervisionado. Muitas vezes, a observação de aulas em período anterior ao estágio supervisionado é recusada ou severamente restrita em outros ambientes (vide BIAZI, GIMENEZ \& STUTZ (2011), onde relatam sua experiência com estágio supervisionado em escolas estaduais). 


\subsubsection{Modelos de formulários para observação de aula}

Como já mencionado, os observadores receberam modelos diferentes de formulários para guiá-los em suas observações. Estes formulários, em número de 03, estão disponibilizados no anexo 2. Os mesmos foram discutidos pelo grupo e os observadores foram estimulados não só a seguir os modelos propostos, mas também sugerir outros ou elaborar modelos próprios num processo de construção de conhecimento compartilhado. Além disto, era possível fazer uso de diferentes formulários nas diversas aulas observadas. Estes modelos de formulários tinham a intenção de servir como exemplos de registros possíveis de informações coletadas que fossem ao mesmo tempo válidas e detalhadas. Com estas observações, tinha-se em mente que os observadores apontariam alguns aspectos específicos que pudessem caracterizar a aula observada, tais como nível, número de alunos, disposição dos alunos na sala durante a aula, postura do professor, insumo fornecido, atividades propostas e formas de correção. Houve preocupação em seguir o caminho de uma observação holística, sem priorização da observação de limitações ou de pontos negativos.

Os relatórios de aulas entregues aos professores formadores, na maioria das vezes, continham observações revistas e sintetizadas. Era possível perceber que muitas informações vistas pelos observadores não foram socializadas no grupo, de tal forma que a construção de conhecimento por parte de cada observador foi individual e seguiu caminhos distintos. Enquanto pesquisadoras, vimos nisso a possibilidade de, ao trabalhar em grupo, ter espaço também para a construção de sentidos particulares.

De certa forma, o que se pretendia com a observação de aulas e o registro dessas observações era estimular o "aprender a aprender", ou ainda, o "aprender a olhar" no sentido proposto por Jorge Larrosa (IN: da SILVA, 2010, p. 80)

\footnotetext{
[a]prender a olhar é racionalizar e estabilizar tanto o olhar quanto o espaço. É acostumar o olho a deslocar-se ordenadamente, a focalizar de forma conveniente, a capturar os detalhes significativos. (...) Um olhar educado é um olhar que sabe onde e o que deve olhar. (...) Aprender a olhar é, portanto, reduzir a indeterminação e a fluidez das formas (...).
}

Entendidas como práticas pedagógicas, as observações de aula são "aquelas nas quais se produz ou se transforma a experiência que as pessoas têm de si mesmas" 
(LARROSA, IN: da Silva, 2010, p. 36). Nestas, “o importante não é que se aprenda algo exterior, um corpo de conhecimentos, mas que se elabore ou reelabore alguma forma de relação reflexiva do 'educando' consigo mesmo" (ibid). Em outras palavras, isto equivale a dizer que o observador não observa aulas para aprender algo, aprender um "como se faz", uma receita, mas para poder refletir sobre a possibilidade de se ver naquela posição, a de professor responsável por uma turma, se questionando e questionando o professor observado acerca das múltiplas escolhas e decisões tomadas antes, durante e depois da aula, pois ele ainda não teve essa oportunidade (pelo menos não no Celin-UFPR). Trata-se da oportunidade de experienciar diferentes agências e perceber as relações de alteridade, ou seja, as relações entre o indivíduo e o outro e a possibilidade de, ao se ver no outro, o indivíduo refletir sobre si mesmo, e se transformar continuamente.

\subsection{As observações de aulas}

O processo de observação de aulas, como já mencionado, se presta como ferramenta tanto para a formação inicial quanto continuada de professores. GIMENEZ, BIAZI \& STUTZ (2011), nos apresentam, na perspectiva da formação inicial, três propostas comumentemente observadas em cursos de licenciaturas para entender o papel do professor: a que postula o modelo do professor artesão, a que postula o modelo de professor que faz uso da aplicação das ciências, e a que postula o modelo do professor reflexivo. Estas três propostas nos parecem exequíveis no contexto de estágio de uma maneira geral e no contexto em que trabalhamos. Da mesma forma, as vemos como adaptáveis a diversos contextos de observação de aulas; por isso optamos por apresentar em linhas gerais o funcionamento destas e sua inserção nos contextos.

$\mathrm{Na}$ primeira proposta, aplicada ao contexto de formação inicial de professores, denominada de modelo de formação do professor artesão, os professores observados dão suas aulas, ou seja, são os artesãos que mostram como se faz, dizem o que fazer e têm a possibilidade de serem imitados pelos observadores em suas práticas futuras. Nesta perspectiva, temos a proposta da imitação de um exemplo fornecido por um "bom" professor. Tal perspectiva, no entanto, é bastante passiva, e limita a possível atuação dos observadores. Isto sem se falar da compreensão do que seria um "bom" professor. 
De acordo com o modelo do professor que faz uso da aplicação das ciências, calcado no rigor analítico e prescritivo, os observadores constroem uma formação sólida com base no estudo de pesquisas sobre ensino e aprendizagem. Estas fontes de informação e referência ajudariam a promover a ligação entre teoria e prática (futura). Em tal proposta, no entanto,

\begin{abstract}
(...) a observação de aulas passa a ter um caráter meramente avaliativo, na qual se verifica apenas a aplicação da teoria vigente; o contexto de atuação do professor é totalmente desconsiderado. Eventuais fracassos são atribuídos à não obediência aos moldes pré-estabelecidos pelas certezas absolutas - produzidas pelo método científico. É natural que com esta postura surjam receios, resistência, hostilidade e falta de confiança por parte do professor-regente com relação à observação de sua prática (BIAZI, GIMENEZ \& STUTZ, 2011, p.61).
\end{abstract}

Para o escopo da nossa pesquisa, entendemos os professores observados como sendo os chamados professores regentes. No entanto, na perspectiva que propusemos, a troca de informações entre observadores e observados sempre foi uma constante, justamente para evitar desconforto por parte daqueles que haviam cedido o seu espaço para que as observações acontecessem. Mesmo assim, consideramos o modelo de aplicação das ciências uma possibilidade restritiva porque o que é estudado na academia leva em consideração a teoria e exemplos aplicados a contextos nem sempre equivalentes aos encontrados pelos professores em sua prática.

Já no modelo do professor reflexivo, temos a junção entre a prática e a teoria. Nesta proposta, a formação é entendida como fundamentação de conhecimentos específicos que precisam estar atrelados às questões e aos problemas encontrados em sala de aula (BIAZI; GIMENEZ \& STUTZ, 2011, p.62). Ainda de acordo com BIAZI; GIMENEZ \& STUTZ (2011), a prática da reflexão como reconstrutora da experiência pode conduzir para novos entendimentos sobre o que é ser professor e possibilitar maior emancipação profissional. No papel de observador reflexivo, portanto, os observadores analisam a situação da aula observada e passam a "abstrair a estrutura que está subjacente àquela aula" (SANTANA \& GIMENEZ, 2005, p.11). 


\subsection{Questionário para levantamento de crenças}

Tanto os observadores quanto os professores observados receberam via correio eletrônico, após o término do segundo período de observações de aulas, um questionário para ser respondido. Os observadores receberam um questionário compreendendo 11 perguntas, sendo que duas destas eram sobre a sua formação (graduando, graduado, etc...) e outra sobre sua experiência no ensino de língua inglesa (vide questionário no anexo 1). Já os professores observados receberam um questionário composto de 15 perguntas, sendo que as duas primeiras também solicitavam informações sobre sua formação e experiência com o ensino de língua inglesa. As informações fornecidas pelos professores observados, porém, não serão analisadas neste artigo.

\section{ANÁLISE DOS DADOS}

Entendemos que o processo de observação de aulas não é apenas uma prática pedagógica extremamente necessária, mas também uma forma de verificar as crenças que os professores em formação têm acerca de ensino e aprendizagem de língua inglesa, contrastando-as com as de professores com um pouco mais de experiência.

Para definir crenças, e sistema de crenças, recorremos mais uma vez a Richards \& Lockhart (1996), quando estes afirmam que tais sistemas são fundados nos objetivos, valores e crenças que os professores possuem em relação ao conteúdo e ao processo de ensino, e sua compreensão dos sistemas nos quais trabalham e seus papéis neles. Estas crenças e valores servem como plano de fundo para muitas das decisões e ações dos professores e constituem o que tem sido definido como "cultura de ensinar" (tradução nossa, 1996, p. 30). ${ }^{5}$

Ainda com base nas contribuições desses autores, entendemos que essas crenças são construídas gradualmente e constituídas de partes objetivas e subjetivas derivadas de diferentes fontes, uma delas sendo a observação de aulas. Ao analisar as respostas

\footnotetext{
${ }^{5}$ No original: "Teachers' belief systems are founded on the goals, values, and beliefs teachers hold in relation to the content and process of teaching, and their understanding of the systems in which they work and their roles within it [sic]. These beliefs and values serve as the background to much of the teachers' decision making and action, and hence constitute what has been termed the "culture of teaching" (RICHARDS \& LOCKHART, 1996, p. 30).
} 
fornecidas pelos observadores, tentamos apontar ocorrências que justifiquem a presença ou ausência das seguintes fontes:

a) A própria experiência como aprendizes de língua estrangeira, que não pode ser ignorada, posto que em inúmeras ocasiões o que pode ter sido percebido na postura de um professor observado, pode ser replicado em outros contextos de sua prática futura. Entendemos isso como sendo uma postura de espelho, na qual o indivíduo imita o que vê e que entende como certo, pois acredita pela observação que realmente deu certo e daria certo em qualquer contexto;

b) A falta de experiência (ainda) do que funciona melhor em cada sala de aula, o que muitas vezes pode ser identificado nas respostas que seguem pela linha "Não sabia que poderia dar certo!" Muitas vezes essa falta de experiência não é tão nociva quanto pode parecer, pois a atitude desses alunos-professores tende a ser mais receptiva a recomendações externas, por exemplo;

c) A falta de prática de sala de aula, e justamente por ela é que a observação é algo tão importante para a formação, pois ao observar o que o professor regente da turma faz, o observador, que está em processo de formação inicial, muitas vezes se coloca no papel do observado, podendo até mesmo desenvolver uma "prática em paralelo".

d) Traços de personalidade, que sempre influenciarão a prática do professor.

e) $\mathrm{O}$ aprendizado baseado em princípios pesquisados, pois a observação de aula é ainda vista como uma ferramenta pouco valorizada em muitos contextos, e, portanto, o insumo recebido quando da formação inicial na graduação é de fundamental importância, não podendo ser negligenciado.

f) Princípios derivados de determinado método ou abordagem, que se refletem nas observações feitas quando essas sugerem que algo poderia ser de determinada forma, ou diferente do que foi, por exemplo.

1.4. Análise das respostas dadas pelos observadores: o exercício da agência docente

As respostas dadas pelos observadores estão apresentadas de forma sucinta no quadro a seguir. Procuramos simplificar as questões feitas para tornar a leitura mais dinâmica. As respostas apresentadas de forma resumida dão conta das questões 03 a 11 do 
REVISTA X, VOLUME 2, 2012

questionário proposto (vide questionário completo no anexo 1), e a nomeação dos cinco observadores se dá pelo uso de letras (A, B, C, D e E).

\begin{tabular}{|c|c|c|c|c|c|}
\hline Questionamentos & A & B & $\mathrm{C}$ & $\mathrm{D}$ & $\mathrm{E}$ \\
\hline $\begin{array}{l}\text { 3.já havia } \\
\text { observado } \\
\text { aulas/como foi }\end{array}$ & $\begin{array}{lrr}\text { Sim. Aulas } & \text { de } \\
\text { professora } & \\
\text { supervisora } & \text { PIBID. } \\
\text { Experiência caótica: } \\
\text { turma com } & 40 \\
\text { alunos e } & 05 \\
\text { observadores } & \text { ao } \\
\text { mesmo tempo. } & \end{array}$ & $\begin{array}{l}\text { Sim. Observei } \\
\text { aulas em um curso } \\
\text { de idiomas. }\end{array}$ & Não. & Não. & $\begin{array}{l}\text { Sim. Quatro aulas de } \\
\text { inglês para alunos de } \\
5^{\mathrm{a}} \text { série. }\end{array}$ \\
\hline $\begin{array}{l}\text { 4.aspectos } \\
\text { positivos de se } \\
\text { observar aulas }\end{array}$ & $\begin{array}{ll}\text { ambiente } & \text { diferente; } \\
\text { espaço para o } \\
\text { observador. }\end{array}$ & $\begin{array}{l}\text { notar o perfil dos } \\
\text { alunos do Celin e } \\
\text { o que esperam das } \\
\text { aulas; professores } \\
\text { acessíveis. }\end{array}$ & $\begin{array}{l}\text { consigo enxergar } \\
\text { elementos que nunca } \\
\text { observei antes. }\end{array}$ & $\begin{array}{l}\text { tenho contato com } \\
\text { o trabalho do } \\
\text { professor dentro e } \\
\text { fora da sala. }\end{array}$ & $\begin{array}{l}\text { observar aulas de } \\
\text { professores } \\
\text { experientes cria um } \\
\text { ambiente seguro para } \\
\text { "extrair" ideias; o } \\
\text { professor serve como } \\
\text { modelo tanto de } \\
\text { coisas que dão certo } \\
\text { como de coisas que } \\
\text { não dão. }\end{array}$ \\
\hline $\begin{array}{l}\text {.aspectos } \\
\text { negativos de se } \\
\text { observar aulas }\end{array}$ & $\begin{array}{l}\text { gostaria de um } \\
\text { acompanhamento } \\
\text { maior no pré/pós } \\
\text { aula. }\end{array}$ & $\begin{array}{l}\text { não ter acesso ao } \\
\text { livro usado. }\end{array}$ & $\begin{array}{l}\text { não houve aspecto } \\
\text { negativo. }\end{array}$ & Nenhum. & $\begin{array}{l}\text { os alunos parecem } \\
\text { não entender o papel } \\
\text { do observador. }\end{array}$ \\
\hline $\begin{array}{l}\text { 6.participação } \\
\text { ativa nas aulas } \\
\text { observadas }\end{array}$ & Não. & Não. & Não. & Sim. & Não. \\
\hline $\begin{array}{ll}\text { 7.se } & \text { não } \\
\text { participou, } \\
\text { gostaria de ter } \\
\text { participado }\end{array}$ & $\begin{array}{l}\text { Dúvida; sou falante } \\
\text { e sinto vontade de } \\
\text { participar" mas } \\
\text { "participando } \\
\text { poderia perder } \\
\text { alguns movimentos } \\
\text { do professor, o que } \\
\text { poderia } \\
\text { comprometer } \\
\text { observação como } \\
\text { um todo. }\end{array}$ & $\begin{array}{l}\text { Não. "O processo } \\
\text { de observação é } \\
\text { uma observação; } \\
\text { participando não } \\
\text { poderia tomar } \\
\text { notas nem } \\
\text { observar como o } \\
\text { professor lida com } \\
\text { a turma". }\end{array}$ & $\begin{array}{lr}\text { Não gostaria } & \text { de } \\
\text { participar; } & \text { não } \\
\text { interagindo eu podia } \\
\text { me roncentrar } \\
\text { somente } & \text { em } \\
\text { observar; minha } \\
\text { interferência } \\
\text { alteraria } \\
\text { andamento da aula. }\end{array}$ & $\begin{array}{l}\text { Participei. } r \text { Foi } \\
\text { bom porque pude } \\
\text { ouvir de perto } \\
\text { suas produções, } \\
\text { mas eles se } \\
\text { distraíram com a } \\
\text { minha presença e } \\
\text { falaram em } \\
\text { português. }\end{array}$ & $\begin{array}{lr}\text { Apesar de } & \text { ter } \\
\text { recebido } & \text { uma } \\
\text { atividade } & \text { para } \\
\text { resolver ao mesmo } \\
\text { tempo que os alunos, } \\
\text { não interagi com eles. } \\
\text { Foi negativo, pois } \\
\text { não pude acompanhar } \\
\text { as } \\
\text { encontradas formas } \\
\text { professor pelo } \\
\text { solucionar as dúvidas. }\end{array}$ \\
\hline $\begin{array}{l}\text { 8.aspectos } \\
\text { positivos em } \\
\text { relação a ter suas } \\
\text { aulas observadas } \\
\text { no futuro }\end{array}$ & $\begin{array}{l}\text { ter a opinião de } \\
\text { alguém de fora que } \\
\text { pode lhe ajudar; } \\
\text { construção } \\
\text { aprendizado } \\
\text { contínuo. }\end{array}$ & $\begin{array}{lr}\text { se feita } & \text { com } \\
\text { seriedade } & \text { a } \\
\text { observação } & \text { pode } \\
\text { auxiliar } & \text { o } \\
\text { professor } & \\
\text { mostrando onde e } \\
\text { quando } & \text { agir } \\
\text { diferente. } & \end{array}$ & $\begin{array}{l}\text { ser alertada de } \\
\text { falhas que não } \\
\text { perceberia sozinha. }\end{array}$ & $\begin{array}{l}\text { como nunca dei } \\
\text { aulas, } \\
\text { necessário ter as } \\
\text { aulas observadas } \\
\text { para me sentir no } \\
\text { caminho certo e } \\
\text { melhorar o que } \\
\text { precisa } \\
\text { melhorado. }\end{array}$ & $\begin{array}{lr}\text { ser observado } & \text { por } \\
\text { colegas } & \text { mais } \\
\text { experientes pode } & \text { ser } \\
\text { enriquecedor quanto } \\
\text { à } \quad \text { troca } & \text { de } \\
\text { experiências. } & \end{array}$ \\
\hline $\begin{array}{l}\text { 9.aspectos } \\
\text { negativos de ter } \\
\text { suas aulas } \\
\text { observadas no } \\
\text { futuro }\end{array}$ & $\begin{array}{l}\text { desconforto inicial } \\
\text { por ter um estranho } \\
\text { na sala. }\end{array}$ & $\begin{array}{lr}\text { os alunos } & \text { se } \\
\text { comportam } & \\
\text { diferente, o que } \\
\text { deixa } \\
\text { observação falha. }\end{array}$ & $\begin{array}{lr}\text { poderia me } & \text { deixar } \\
\text { nervosa } & \mathrm{e} \\
\text { apreensiva. } & \end{array}$ & $\begin{array}{ll}\text { ansiedade, muita } \\
\text { ansiedade. }\end{array}$ & $\begin{array}{l}\text { a observação cria um } \\
\text { ambiente artificial na } \\
\text { aula. É possível que } \\
\text { eu me sentisse } \\
\text { insegura. }\end{array}$ \\
\hline $\begin{array}{lr}10 . & \text { diferença } \\
\text { entre ter as aulas } \\
\text { observadas por } \\
\text { um colega } \\
\text { por ou } \\
\text { coordenador (ou } \\
\text { chefe) }\end{array}$ & $\begin{array}{l}\text { a questão da } \\
\text { hierarquia; ambos } \\
\text { têm suas vantagens. }\end{array}$ & $\begin{array}{l}\text { observação de um } \\
\text { colega seria mais } \\
\text { tranquila; com o } \\
\text { coordenador há a } \\
\text { pressão que não } \\
\text { faz parte das } \\
\text { aulas. }\end{array}$ & $\begin{array}{l}\text { a sensação é de que } \\
\text { o colega está ali para } \\
\text { ajudar e o chefe para } \\
\text { avaliar. }\end{array}$ & $\begin{array}{l}\text { um colega está } \\
\text { mais próximo de } \\
\text { um amigo. No } \\
\text { fundo, a única } \\
\text { diferença seria a } \\
\text { quantidade de } \\
\text { nervosismo. }\end{array}$ & $\begin{array}{lr}\text { uma } & \text { diferença } \\
\text { hierárquica } & \text { clara. } \\
\text { Tentaria impressionar } \\
\text { o chefe. Não havendo } \\
\text { competição } & \text { entre } \\
\text { colegas, } & \text { ser } \\
\text { observada por um } \\
\text { colega seria menos } \\
\text { incômodo. }\end{array}$ \\
\hline $\begin{array}{l}\text { 11.os } \\
\text { formulários de } \\
\text { observação de } \\
\text { aula ajudaram na } \\
\text { tarefa ou não. }\end{array}$ & $\begin{array}{lr}\text { sim; credibilidade } \\
\text { atestada; os modelos } \\
\text { não } & \text { foram } \\
\text { apresentados } & \text { como } \\
\text { algo fixo; } & \text { grande } \\
\text { ajuda. } & \\
\end{array}$ & $\begin{array}{lr}\text { sim; quais } \\
\text { aspectos das aulas } \\
\text { deveriam receber } \\
\text { mais atenção; } \\
\text { anotações mais } \\
\text { organizadas. }\end{array}$ & $\begin{array}{l}\text { ajudou; existem } \\
\text { coisas que eu nem } \\
\text { sabia que poderiam } \\
\text { ser observadas. }\end{array}$ & $\begin{array}{l}\text { mais ou menos; } \\
\text { ajudou para ter } \\
\text { uma ideia do que } \\
\text { seria mais } \\
\text { importante } \\
\text { observar. }\end{array}$ & $\begin{array}{l}\text { sim; servem de } \\
\text { suporte; } \\
\text { guidelines }\end{array}$ \\
\hline
\end{tabular}

Quadro 2 - Resumo das informações 
$\mathrm{Na}$ análise desses dados, umas das perspectivas de maior relevância para nós quando da reflexão sobre os mesmos foi a das diferentes agências exercidas pelos participantes. Para deixar clara esta perspectiva, retomamos aqui o entendimento de agência. Para Vilson Leffa (2011), agência é

(...) uma questão de perspectiva: olhando do ponto de vista do agente, os humanos podem às vezes ser percebidos como mecanismos de mediação, do mesmo modo como os artefatos podem ser percebidos como agentes. A agência não é uma característica permanente ou intrínseca de uma pessoa ou objeto; a agência é um atributo temporário concedido a alguém ou a alguma coisa (LEFFA, 2011, p. 277).

E como já mencionado na página 2 deste texto, ALMEIDA (2011) lembra que para conceituar o termo agência é preciso considerar os diferentes papéis exercidos pelos participantes da pesquisa ao longo de todo o processo, já que diferentes identidades vão sendo reveladas e assumidas em situações diversas.

É possível perceber que a atribuição do papel de observadores de aulas propiciou o desempenho de outras agências, nem sempre tão claras para os participantes, tais como: a de professor, a de observador participante, e a de aprendiz.

O participante A demonstrou seu interesse em ser também um pouco professor ao longo do processo, e apontou em sua fala o conflito que poderia existir se exercesse simultaneamente estas duas agências: a de observador e a de professor - "sinto vontade de participar, mas participando poderia perder alguns movimentos do professor, o que poderia comprometer a observação como um todo". O mesmo conflito pode ser identificado através da análise da fala da participante E: "a observação cria um ambiente artificial na aula. É possível que eu me sentisse insegura" (como professora sendo observada). Já a participante D observa que ao participar como professora pode ouvir as produções dos alunos, mas revela também que "eles (os alunos) se distraíram com a minha presença e falaram em português."

Com relação à possibilidade de um observador participante, alguns informantes se mostram reticentes em assumir um papel mais ativo nas aulas observadas e até mesmo ideias pré-concebidas a respeito de observações participativas. Conforme C, "não gostaria de participar; não interagindo eu podia me concentrar somente em observar; minha interferência alteraria o andamento da aula." Como prever que efetivamente a observação mudaria o curso do planejamento? Até que ponto o desempenho de agências pode ser 
claramente delimitado? B parece acreditar em uma delimitação muito clara, "o processo de observação é uma observação; participando não poderia tomar notas nem observar como o professor lida com a turma."

Enquanto aprendizes, os informantes demonstraram em suas falas uma percepção holística do processo na medida em que o pensar e o repensar são realimentados ao longo do percurso. Neste sentido, diz A: "ter a opinião de alguém de fora que pode lhe ajudar ajuda na construção e aprendizado contínuo." Já B defende que, ao ser observado, um professor pode "ser alertado de falhas que não perceberia sozinha." E D acrescenta "ter as aulas observadas para me sentir no caminho certo $e$ melhorar o que precisa ser melhorado." A participante E ressalta ainda a importância da troca de experiências não sem, contudo, apontar para a artificialidade do ambiente de sala de aula onde, hipoteticamente, ela poderia se sentir insegura ao ser observada.

Além disso, quando da avaliação do processo de observação de aulas, os observadores apontaram que este processo é bastante positivo, pois os professores foram acessíveis (observadora B). Além disso, a observadora D apontou que foi possível "ter contato com o trabalho do professor dentro e fora da sala". Em uma das contribuições, a da observadora E, ficou clara a identificação do modelo do professor artesão, ou ainda da postura de espelho, em que o aprendiz verifica algo que o artesão faz, entende essa postura como correta e, possivelmente, a imita. Nas palavras da observadora, observar aulas de professores "experientes cria um ambiente seguro para extrair ideia". A reflexão oportunizada pela observação de aulas fez com que esta observadora acrescentasse: " $O$ professor serve como modelo tanto de coisas que dão certo como de coisas que não dão." Ou seja, é possível verificar a que escolha pela postura de espelho não seria exclusivamente adotada como válida em sua prática.

Já em relação aos aspectos negativos do processo de observação de aulas, duas observadoras, C e D, apontaram não haver aspectos negativos, enquanto que B observou ser negativo "não ter acesso ao livro usado", e A apontou que "gostaria de um acompanhamento maior no pré/pós aula". Ainda E chamou a atenção para o fato de que "os alunos parecem não entender o papel de observador". O fato de os alunos se comportarem diferente com a presença de um observador também foi levantado pela observadora B. Entendemos que uma possível justificativa para essa postura por parte dos alunos seja o fato de que os observadores não interagiram com eles, e acreditamos que essa 
situação pode ser contornada com uma conversa entre alunos, observador e professor observado. Em relação ao acompanhamento pré/pós aula, entendemos que se esse procedimento fosse adotado, os ganhos em termos de observação mais direcionada de detalhes e encaminhamentos poderia ser maior. Por outro lado, o não acompanhamento da preparação da aula se apresenta como um desafio para o observador, que se vê em uma posição em que precisa entender o que está sendo feito, como isto foi planejado, e antecipar possíveis objetivos.

Portanto, aspectos diversos, tanto positivos como negativos, foram objeto de discussão tanto do processo de observação de salas de aula, quanto das diferentes agências desempenhadas pelos informantes da pesquisa. São esses dados que nos levam a algumas conclusões e pontos para discussão.

\section{CONCLUSÕES E PONTOS PARA DISCUSSÃO}

Apesar de ser um importante componente da prática de ensino, a natureza e as limitações das observações precisam ser consideradas, pois ensinar é uma atividade complexa e dinâmica; e durante uma aula muitas coisas podem ocorrer simultaneamente. Mesmo o observador mais atento pode não perceber todas as variáveis. Isto sem considerar a própria presença de um observador que pode influenciar o andamento de uma aula (RICHARDS \& FARRELL, 2011), como percebido pelos observadores.

Além disso, mesmo ao assumir agência de observador, cada pessoa poderá também exercer diferentes agências que não se constituem em papéis fixos e que não se alteram. As agências são, sobretudo, construções fluidas em constante mutação a partir dos ambientes diferenciados onde ocorrem e das interações com outros indivíduos e as agências destes.

Ao se estabelecer essa relação entre a observação de aula e as diversas agências desempenhadas pelos observadores, é possível constatar também a impossibilidade de receitas prontas, de modos de agir, aplicáveis a toda e qualquer situação, já que cada momento será único e dependerá de uma postura crítica e aberta para mudança de todos os envolvidos, aqui incluídos o professor formador, os estagiários observadores e os professores observados, que poderão inclusive ter seus papéis trocados. Entendemos que 
não há receitas prontas para que o professor de língua inglesa seja um bom profissional na área, mas também acreditamos que a oportunidade de observar aulas, se reconhecer ou não como professor na situação observada, e a troca de informações e questionamentos entre professores com mais e menos experiência possibilita o exercício da agência de forma mais segura.

Trata-se, portanto, de dar voz e vez a todos propiciando um ambiente que possa contribuir para a formação de professores enriquecendo os procedimentos adotados e gerando transformações constantes.

Em relação aos professores observados, uma vez que o Celin é um espaço de formação inicial e continuada, onde se está em constante aprendizado, pudemos constatar que a observação de aulas oportunizou uma autorreflexão para os professores observados, que ao terem a oportunidade de ter um olhar diferente sobre a sua prática, ampliaram seu processo de crescimento profissional.

\section{REFERÊNCIAS}

ALMEIDA, Mariza Riva de. Um olhar intercultural na formação de professores de língua estrangeiras. Curitiba: UFPR. Tese (Doutorado), 2011.

BIAZI, Terezinha M. D.; GIMENEZ, Telma \& STUTZ, Lídia. “O papel da observação de aulas durante o estágio supervisionado de inglês". Revista SIGNUM: Estudos Linguísticos, Londrina, no 14/1. Pp. 57-78, Jun. 2011.

CHIZZOTTI, Antonio. Pesquisa qualitativa em ciências humanas e sociais. Petrópolis, RJ: Vozes, 2006.

FARRELL, Thomas S. C. Critical Incidents in ELT initial teacher training. ELT Journal Volume 62/1. Oxford University Press. (doi:10.193/elt/ccm072). Pp. 03-10, January 2008.

FREIRE, Paulo. Pedagogia do Oprimido. Coleção O Mundo, Hoje. v. 21. Rio de Janeiro: Paz e Terra, 1983.

FREIRE, Maximina M. "O estágio de observação e a formação docente sob a perspectiva da complexidade". IN: SILVA, Kleber Aparecido da et al. A Formação de Professores de Línguas: Novos Olhares - Volume I. Campinas: Pontes. Pp. 265-284, 2011.

LARROSA, Jorge. "Tecnologias do eu e Educação" IN: da Silva, Tomaz Tadeu. O sujeito da Educação. Estudos Foucaultianos. Petrópolis: Vozes, 2010. Pp. 35-86. 
RICHARDS, Jack \& FARRELL, Thomas. Practice Teaching. A reflective teaching. Cambridge: CUP, 2011.

RICHARDS, Jack \& LOCKHART, Charles. Reflective teaching in second language classrooms. Cambridge: CUP, 1996.

SANTANA, I.; GIMENEZ, Telma. A abordagem reflexiva na visão de formadores de professores de inglês. UNOPAR, Cient., Ciênc. Hum. Educ., Londrina, v. 6, n. 1, p.7-13, Jun. 2005.

SANTOS FILHO, J.C. Pesquisa Quantitativa versus Pesquisa Qualitativa: o desafio paradigmático. IN: GAMBOA, S. S. Pesquisa educacional: quantidade - qualidade. São Paulo: Cortez. 1997. 


\section{ANEXO 1}

Questionário para os observadores do Celin:

Idade:

Sexo: $\overline{(\quad \text { ) feminino }}($ ) masculino

1. Sua situação atual (se for o caso, marque mais de uma alternativa):

( ) aluno(a) de graduação em Letras (habilitação: (Semestre:

( ) aluno(a) de graduação do curso de (Semestre:

( ) formado(a) em Letras (habilitação:

( ) formado(a) em

2. Sua experiência no ensino de Língua Inglesa:

( ) dei aulas particulares por (período de tempo)

( ) dei aulas em escola de ensino fundamental por (período de tempo)

( ) dei aulas em escola de ensino médio por (período de tempo)

( ) dei aulas em cursos de idiomas por (período de tempo)

( ) não tenho experiência em ensino de Língua Inglesa ainda

3. Você já havia observado aulas antes (que não no Celin)? Se sim, como classifica a experiência? Por quê?

4. Quais foram, em linhas gerias, os aspectos positivos de se observar aulas no Celin?

5. Quais foram, em linhas gerais, os aspectos negativos de se observar aulas no Celin?

6. Você participou ativamente de alguma atividade proposta na aula? Se sim, quais foram os aspectos positivos e negativos dessa experiência?

7. Se não participou, gostaria de ter participado? Por quê?

8. Quais seriam os aspectos positivos de ter suas aulas observadas no futuro?

9. Quais seriam os aspectos negativos de ter suas aulas observadas no futuro?

10. Na sua percepção, qual seria a diferença entre ter suas aulas observadas por um colega, ou por um coordenador (ou chefe)?

11. O fato de haver alguns modelos de registro de observação de aulas ajudou na sua experiência de observação ou não? Por quê? 
ANEXO 2

\section{Exemplo 1 - OBSERVATION SHEET}

Please write your observation notes using these headings on A4 paper. For each observation you should write up to two sides.

1. Date and time of class.

Name of teacher.

2. $\mathrm{N}^{\mathrm{o}}$ of students present.

Main nationalities.

3. Main aims of lesson. (as you see them)

4. $\underline{\text { Skills }}$ - which were being practiced? (Listening/Speaking/Reading/Writing)

5. Activities - list them and indicate the teacher/student interaction (TSI)

6. Resources - which did the teacher use? (books, worksheets, tapes, flashcards, etc) How were they exploited?

7. Layout. Sketch the layout of the class (position of teacher/student/whiteboard, etc). How did this arrangement affect the way the lesson went? Was the layout changed during the lesson?

8. What I particularly liked.

9. Difficulties encountered. What particular difficulties, if any, arose and how did the teacher deal with them?

10. Personal Repertoire. What particular feature/features of this lesson do you feel ready to incorporate in your teaching? 


\section{Exemplo 2 - PEER OBSERVATION TASK}

TEACHER:

OBSERVER:

DATE:

CLASS PROFILE:

TIME:

As you observe the lesson, note down several things you would like to 'steal' from this teacher and the lesson in order to make them part of your own teaching. This may include personal qualities, teaching skills, and techniques, activities, classroom atmosphere, etc. Include notes to help you remember any important details. You may want to record why you felt good about the stolen goods. Finally, choose something you would like to give this teacher in return for your many thefts.

Stolen item 1:

Description of item:

I stole this item because:

Stolen item 2:

Description of item:

I stole this item because:

Stolen item 3:

Description of item:

I stole this item because:

I'd like to give you:

I think you'd like this because:

(C) Jim Scrivener 1994 


\section{Exemplo 3 - OBSERVAÇÃO DE AULAS}

Modelo para feedback das observações:

\begin{tabular}{|l|l|l|}
\hline Observador: & Língua: & Nível: \\
\hline Professor: & Horário: & Número de alunos: \\
\hline Data: & & \\
\hline Material utilizado: & \\
\hline Descrição da aula: & \\
\hline Atividades interessantes: & \\
& \\
\hline Pontos que modificaria: & \\
\hline
\end{tabular}

